\title{
What are the prognostic factors affecting 30-day mortality in geriatric patients with respiratory failure in the Intensive Care Unit?
}

\author{
Mustafa Ozgur Cirik ${ }^{1}$, Derya Yenibertiz ${ }^{2}$
}

\begin{abstract}
Objective: We aimed to investigate the prognostic factors related to 30 day mortality of elderly patients with respiratory failure in the intensive care unit (ICU).

Methods: We performed a single centre, retrospective study and analyzed the main variables and outcomes of 238 geriatric patients admitted to an ICU with ARF between December 2017- January 2019 in Chest Disease Hospital, were included and classified as survivors and nonsurvivors. Main characteristics, laboratory datas, severity and nutrition scores were evaluated and logistic regression analysis were used. Results: The nonsurvivor group included 110 cases (40\% female,) with a median age of 79 , had higher scores in the followings; Acute Physiology Chronic Health Evaluation II score (APACHE-II) $(p<0.001)$, Charlson Comorbidity Index $(\mathrm{CCl})(p<0.001)$, Sequential Organ Failure Assessment score $(p<0.001)$. The inotropic support requirement was also higher in the nonsurvivor group (48,2\%). As a comorbidity, malignancy and Type-I respiratory failure were higher in the nonsurvivor group $(p=0.03, p<0.001)$. The overall 30-day mortality was $46 \%$. Blood urea nitrogen, procalsitonin, C-reactive protein and creatinine levels were higher in the nonsurvivor group $(p<0.001)$. However, albumin $(p<0.001)$, BMI $(p=0.03)$ and longer hospital stay $(p$ $<0.001$ ) were higher in the survivor group. Inotropic support, APACHE-II score and CCI were independently related to increased mortality risk, whereas albumin was associated with decreased mortality risk.

Conclusion: High APACHE II score, low $\mathrm{CCl}$, low albumin levels and the requirement for inotropic support were found to be independently risk factors of 30-day mortality in the geriatric patients with respiratory failure in ICU.
\end{abstract}

KEYWORDS: 30-day Mortality, Geriatric patient, Intensive Care Unit, Prognostic factors.

doi: https://doi.org/10.12669/pjms.37.1.3189

How to cite this:

Cirik MO, Yenibertiz D. What are the prognostic factors affecting 30-day mortality in geriatric patients with respiratory failure in the Intensive Care Unit? Pak J Med Sci. 2021;37(1):15-20. doi: https://doi.org/10.12669/pjms.37.1.3189

This is an Open Access article distributed under the terms of the Creative Commons Attribution License (http://creativecommons.org/licenses/by/3.0), which permits unrestricted use, distribution, and reproduction in any medium, provided the original work is properly cited.

1. Mustafa Ozgur Cirik,

Department of Anesthesiology,

2. Derya Yenibertiz, Department of Pulmonology,

1-2: University of Health Sciences,

Ataturk Chest Diseases and Chest Surgery Training and

Research Hospital, Ankara, Turkey.

Correspondence:

Derya Yenibertiz,

Department of Pulmonology,

University of Health Sciences,

Ataturk Chest Diseases and Chest Surgery Training and

Research Hospital, Ankara, Turkey.

Email: yenibertizderya@gmail.com

* Received for Publication:

July 29,2020

* Accepted for Publication:

October 15, 2020

\section{INTRODUCTION}

With the increasing of longevity, the geriatric population has also been rising all over the world in the past few decades. The World Health Organization (WHO) declared that by 2050, approximately $16 \%$ of the world population, will be equal or more than 65 years old. ${ }^{1}$ These elderly population are representing majority of the patients admitted to ICU. ${ }^{2}$ The incidence of acute respiratory failure (ARF), the major indication of hospitalization in the ICU, increases exponentially with age. ${ }^{3-5}$ The relationship between prognosis and the age of the critically ill patients has been investigated in detail for 
the Iast three decades. Advanced aged patients had higher mortality rates than younger aged patients in prospective studies. ${ }^{6-9}$ It is known that geriatric patients are more likely to die in the ICU and age is independent risk factor for mortality. ${ }^{10}$ Diseases have atypical presentations in the geriatric population and there are lots of co-morbidities that increase the mortality rate for in this age group.

To determine the prognostic factors affecting mortality is crucial for the management of diagnosis and treatment of geriatric patients. Therefore, much more clinical studies and evaluations are needed to define the prognostic factors of geriatric patients with respiratory failure in the intensive care unit. We aimed to investigate the outcomes of geriatric patients treated for ARF in the ICU and to determine the prognostic factors related with 30-day mortality rate in this study.

\section{METHODS}

We performed a single centre, retrospective study and analyzed the main variables and outcomes of 238 geriatric patients admitted to an ICU with ARF between December 2017- January 2019 in Chest Disease Hospital. The study was approved by the medical training committee of the hospital (approval number: 659) on 16th of January, 2020 and the informant consent was not obtained because of the retrospective nature of the study. Geriatric patients were defined as aged 65 years old and over. Patients, referred to another clinic or hospital during one month (n:27), died within 24 hours after admission $(n: 8)$ and had missing data (n:10) were excluded from the study. Age, gender, comorbidities, hospital stay in length in ICU, body mass index (BMI), duration of mechanical ventilation, readmission to ICU, type of respiratory failure (Type-1 or Type-2), inotropic support, laboratory parameters at the time of diagnosis (biochemistry, hemogram, procalsitonin, C-reactive protein) were recorded from the patient files. Severity scores such APACHE-II score, the Sequential Organ Failure Assessment (SOFA) score, and Charlson Comorbidity lndex (CCI) and nutrition scores such as Nutrition Risk Screening (NRS) 2002; Nutrition Risk in Critically ill (Nutric Score) obtained within the first 24 hours of ICU admission. Patients were classified into two groups; survivors and non-survivors according to 30-day mortality. The thirty-day mortality was defined as mortality due to any cause during hospitalization in the ICU or after discharge from ICU to other medical ward or to home within 30 days.

Statistical Analysis: The Statistical package program for the Social Sciences (SPSS) version 21.0 was used for the statistical analysis. The continuous variables were assessed by Kolmogorov-Smirnov test and histograms to find out if their distributions were normal or not. The normally distributed numerical parameters were analyzed by student's t-test and others were analyzed by Mann-Whitney $U$ test. The categorical variables were compared by Chisquares or Fisher's Exact test. A p $<0.05$ was considered as statistically significant.

For the logistic regression analysis, univariate analysis was performed first, and accordingly multivariate logistic regression analysis with a backward stepwise approach were done. HosmerLerneshow goodness of fit statistics were used to assess model fitness.

\section{RESULTS}

Between December 2017 and January 2019, a total of 351 patients were admitted with the diagnosis of ARF in the one of the third level ICU of our hospital. A total of 238 geriatric patients found to be over 65 years old (male: 136, female: 102) analyzed in the study. Invasive mechanical ventilation was applied to 111 patients and noninvasive mechanical ventilation to 127 patients. Patients were classified into two groups survivors and non-survivors according to 30-day mortality. The main characteristics and laboratory data of the participants are shown in Table-I.

BMI, Body Mass Index, categorical variables were presented as $\mathrm{n}(\%)$, skew distributed ones presented as median (min-max) APACHE-II, Acute Physiology and Chronic Health Evaluation-2; SOFA, The Sequential Organ Failure Assessment; BUN, Blood Urea Nitrogen; GFR, Glomerular Filtration Rate; CRP, C-Reactive Protein; variables were presented as median (min-max) NRS, Nutrition Risc Screening; Nutric, Nutrition Risk in Critically ill.

The survivor group included 128 patients (58 female, $45.3 \%)$ with a median age of 77 (65-95 years) and non-survivor group consisted of 110 cases (44 female, $40 \%$ ) with a median age of 79 (65-95 years). All co-morbidities of the patients 
The assessment of Geriatric Patients in Intensive Care Unit

Table-I: Main characteristics and laboratory data of the patients.

\begin{tabular}{|c|c|c|c|}
\hline & Survivors $(n=128)$ & Non-survivors $(n=110)$ & p-value \\
\hline Age & $77(65-95)$ & $79(65-95)$ & 0.05 \\
\hline Female sex. $n,(\%)$ & $58(45.3)$ & $44(40)$ & 0.36 \\
\hline Malignancy. n, (\%) & $10(7.8)$ & $18(16.8)$ & 0.03 \\
\hline Charlson Comorbidity Index & $6(4-13)$ & $7(4-13)$ & $<0.001$ \\
\hline APACHE-2 score & $20(10-34)$ & $26(13-48)$ & $<0.001$ \\
\hline SOFA score & $5(4-8)$ & $8(4-17)$ & $<0.001$ \\
\hline BMI. $\mathrm{kg} / \mathrm{m}^{2}$ & $26(12-53.3)$ & $24.15(13.80-46.80)$ & 0.03 \\
\hline NRS 2002 score & $5(2-6)$ & $5(4-6)$ & 0.70 \\
\hline Inotropic support. $\mathrm{n},(\%)$ & $12(9.4)$ & $53(48.2)$ & $<0.001$ \\
\hline Length of stay in hospital (d) & $16(1-93)$ & $11(1-60)$ & $<0.001$ \\
\hline Length of stay in intensive care unit (d) & $3(1-50)$ & $4(1-34)$ & 0.44 \\
\hline Re-admission to intensive care unit. $n,(\%)$ & $19(14.8)$ & $9(8.3)$ & 0.11 \\
\hline Duration of mechanical ventilation (d) & $3(1-48)$ & $3(1-34)$ & 0.556 \\
\hline Type-I respiratory failure, $\mathrm{n},(\%)$ & $34(26.6)$ & $54(49.1)$ & $<0.001$ \\
\hline Type 2 respiratory failure, $n,(\%)$ & $94(73.4)$ & $56(50.9)$ & $<0.001$ \\
\hline BUN, mg/dL & $31(10-137)$ & $40,5(10-125)$ & $<0.001$ \\
\hline Serum Creatinine, $\mathrm{mg} / \mathrm{dL}$ & $0.9(0.3-6.5)$ & $1.2(0.4-5.2)$ & $<0.001$ \\
\hline GFR, $\mathrm{ml} / \mathrm{dk} / 1,73 \mathrm{~m}^{2}$ & $67(5-116)$ & $47.5(9-105)$ & $<0.001$ \\
\hline Albumin, gr/dL & $3.3(1.6-4.7)$ & $2.9(1.6-4.2)$ & $<0.001$ \\
\hline $\mathrm{CRP}, \mathrm{gr} / \mathrm{dL}$ & $3.9(0.08-33.6)$ & $8.5(0.01-37.9)$ & $<0.001$ \\
\hline Procalcitonin, ng/mL & $0.15(0-25.3)$ & $0.68(0-97)$ & $<0.001$ \\
\hline Leukocytes, $\times 1000$ cells $/ \mathrm{mm}^{3}$ & $10.4(3.5-97.5)$ & $12(0.15-110)$ & 0.11 \\
\hline NRS 2002 score & $5(2-6)$ & $5(4-6)$ & 0.70 \\
\hline Nutric score & $5(2-8)$ & $7(3-9)$ & $<0.001$ \\
\hline
\end{tabular}

were recorded and the number of accompanying malignancies was significantly higher in the nonsurvivors $(p=0.03)$. Compared with the survivor group, non-survivor group had a higher CCI ( $\mathrm{p}$ $<0.001)$, APACHE- II score $(\mathrm{p}<0.001)$, SOFA score $(\mathrm{p}<0.001)$. Almost half of the non-survivor group $(48,2 \%)$ required inotropic support and it was significantly higher in non-survivor group $(\mathrm{p}<0.001)$. Survivor group had a significantly higher BMl $(\mathrm{p}=0.03)$ and length of stay in hospital $(\mathrm{p}<0.001)$. The 30 -day mortality rate was $46 \%$ in ICU. While median BUN, creatinine, CRP and procalsitonin levels were significantly higher in the non-survivor group, median albumin level was significantly higher in the survivor group. NRS 2002 was similar in both groups but Nutric scor was significantly higher in the non survivor group.

The following factors such as BMI, presence of malignity, inotropic support, presence of Type1 respiratory failure, APACHE-II score, CCI, Creatinine, CRP, albumin, were put into the multivariate logistic regression analysis to detect the possible independent parameters that affects 30-day hospital mortality. Variables eligible for inclusion in the multivariate analysis were tested for collinearity. Logistic regression analysis demonstrated that inotropic support, APACHE- 
Mustafa Ozgur Cirik et al.

Table-II: Independent predictors of 30-day hospital mortality.

\begin{tabular}{lcccc}
\hline & \multicolumn{2}{c}{ Unadjusted } & \multicolumn{2}{c}{ Adjusted } \\
\hline Risk Factors & OR $(95 \%$ CI $)$ & $p$ & OR $(95 \%$ CI) & $p$ \\
Inotropic support & $8.98(4.45-18.14)$ & $<0.001$ & $5.29(2.33-12.00)$ & $<0.001$ \\
APACHE-II & $1.16(1.10-1.22)$ & $<0.001$ & $1.12(1.06-1.19)$ & $<0.001$ \\
Charlson Comorbidity Index & $1.60(1.35-1.89)$ & $<0.001$ & $1.25(1.02-1.54)$ & 0.032 \\
Albumin & $0.22(0.12-0.38)$ & $<0.001$ & $0.37(0.19-0.73)$ & 0.004 \\
\hline
\end{tabular}

II score, and CCI were independently related to increased mortality risk, whereas albumin was associated with decreased mortality risk. The results of logistic regression analysis are summarized in Table-II.

OR: odds ratio, 95\% CI: 95\% confidence interval; The p-value of the Hosmere-Lemeshow test was 0,255 , the following factors were entered into the multivariate logistic regression analysis: BMI, presence of malignity, inotropic support, presence of Type-I respiratory failure, APACHE-II score, Charlson Comorbidity Index, Creatinine, CRP, albumin.

\section{DISCUSSION}

Geriatric patients are frequent users of the intensive care units and a significant portion of these patients are over of the age 65 worldwide. ${ }^{11}$ We investigated the outcomes and the prognostic variables associated with mortality rate within 30 days of hospitalization in 238 geriatric patients $(67,6 \%$ of all patients) with ARF. We have identified many poor prognostic factors of those population, including lowness of BMI, albumin and GFR, accompany of malignancy as a comorbidity, presence of Type-I respiratory failure, receiving inotropic support and APACHEII score, SOFA score, CCI, CRP and procalsitonine levels. Several studies have investigated the outcomes of critically ill elderly patients from a different perspective. ${ }^{12-14}$ In our study, we wanted to emphasize the prognostic factors in geriatric patients hospitalized with respiratory failure in the chest diseases hospital. We also consider that knowing the factors affecting the mortality of this specific patient group, which constitutes the majority of the intensive care patient population, affects the outcomes of the intensive care units. While 30-day mortality rate of the all patients of our ICU was $40 \%$, it was $46 \%$ among geriatric patients. This rate was compatible with the literature, as in the study of Chih-Cheng Lai et al. ${ }^{4}$ Because our hospital is a chest disease hospital, all of our intensive care patient population consisted of those diagnosed with respiratory failure and as expected the mortality rate of this risky population is high. Nutritional assesment is a good predictor of the clinical outcome in the patients above the age of 65 admitted to the ICU. As in the study of Onal et al., low levels of BMI and albumin were found to be poor prognostic factors in determining the 30-day mortality of the geriatric patients in our study too. ${ }^{15}$ Nutrition Risk Screening-2002 (NRS2002) and the Nutrition Risk in the Critically ill (NUTRIC) are major instruments for nutrition risk assessment in critically ill patients. ${ }^{16}$ We used either tool for evaluation of nutrition status. While NRS 2002 was similar in both groups, Nutric scor was significantly higher in the non survivor group. We think that Nutric score has better distinctive ability in determining mortality risk in intensive care patients due to including disease severity parameters.

The APACHE-II score is still effectively used in various patient groups to assess the severity and predict the prognosis of patients admitted to ICU. Several studies have reported the relationship between the mortality rate of critically ill patients and the APACHE-II score was found to be related with poor health status and a worse prognosis. ${ }^{17-21}$ The severity of illness during admission to ICU was assessed by using the APACHE II score system in our study and our findings were compatible with these studies. The CCI is first defined as an index of multiple comorbidities including 22 items to predict 1 year mortality in internal medicine patients. ${ }^{22}$ In our study, CCI was found as positively correlated with 30-day mortality (OR 1.25, $\mathrm{p}=0.032$ ). The SOFA score is used to assess organ dysfunction of six vital organs and higher scores are known to be associated with more severe disease and a 
higher mortality. ${ }^{23}$ In our study SOFA score was also correlated with 30 -day mortality ( $p<0.001$ ). Kuo-Chin Kao et al. and Katsutoshi Ando et al. reported that the $\mathrm{CC} 1$ and SOFA were significantly positively correlated with hospital mortality. ${ }^{24,25}$ We suggest that all these severity indices can be used in 30-day mortality estimation according to the clinician's decision.

lnotropic support was found as independent risk factor related with adverse outcomes in geriatric patients admitted to ICU in Orsini J et $\mathrm{al}^{\prime} \mathrm{s}^{26}$ study and it was independently associated with 30-day mortality in our study too. The patients applied inotropic support should be followed closely in terms of early treatment and interventions.

PCT and CRP are well-known markers of bacterial infections, and can be used to predict increased mortality rate in critically ill patients. Nevertheless they were shown to be good diagnostic markers for patients with suspicion of sepsis and can prompt the severity of sepsis..$^{27-30}$ The presence of sepsis is associated with extremely high mortality in ICU. As expected, the CRP and PCT levels were also detected to be higher in the non-survivor group but we didn't evaluate sepsis rate in this study.

We think that this study is valuable as the factors affecting the 30-day mortality of geriatric patients in the respiratory ICU of the chest diseases hospital were evaluated and our results reinforce present evidence on predictive factors of mortality in geriatric patients treated in ICU.

Limitations of the study:, It was a retrospective study. Secondly, The sample size was relatively small and the study was conducted at a single center. We didn't classified the geriatric patients into age groups and we didn't determine the long-term survival of geriatric patients. We also didn't evaluate the level of cognition functions of the geriatric patients because of the retrospective nature of the study.

\section{CONCLUSION}

The 30-day mortality rate was $46 \%$ and risk factors associated with the higher mortality of specific population treated in ICU were higher APACHE scores, CCI, lower albumin and presence of inotropic support in this study. Our findings may help physicians predict 30-day mortality and also facilitate to manage the diagnose and treatment of geriatric patients with respiratory failure in ICU.
Funding sources: All support for this study came from institutional and departmental resources.

Conflict of interest: None.

\section{REFERENCES}

1. Chen WL, Chen CM, Kung SC, Wang CM, Lai CC, Chao CM. The outcomes and prognostic factors of acute respiratory failure in the patients 90 years old and over. Oncotarget. 2018;9(21):15817. doi: 10.18632/ oncotarget.24051

2. Martin-Loeches I, Guia MC, Vallecoccia MS, Suarez D, Ibarz M, Irazabal M, et al. Risk factors for mortality in elderly and very elderly critically ill patients with sepsis: a prospective, observational, multicenter cohort study. Ann Intensive Care. 2019;9(1):26. doi: 10.1186/ s13613-019-0495-x

3. Jean-Yves F. Acute respiratory failure in the elderly. Crit Care. 2006;10(4):151. doi: 10.1186/cc4982

4. Lai CC, Tseng KL, Ho CH, Chiang SR, Chen CM, Chan KS, et al. Prognosis of patients with acute respiratory failure and prolonged intensive care unit stay. J Thorac Dis. 2019;11(5):2051-2057. doi: 10.21037/jtd.2019.04

5. Behrendt CE. Acute respiratory failure in the United States: Incidence and 31-day survival. Chest 2000;118 (4):11001105. doi: 10.1378/chest.118.4.1100

6. Le Gall JR, Lemeshow S, Saulnier F. A new Simplified Acute Physiology Score (SAPS II) based on a European / North American multicenter study. JAMA. 1993;270:29572963. doi: 10.1001/jama.270.24.2957

7. Knaus WA, Draper EA, Wagner DP, Zimmerman JE. APACHE II: a severity of disease classification system. Crit Care Med. 1985;13:818-829.

8. Knaus WA, Wagner DP, Draper EA, Zimmerman JE, Bergner M, Bastos PG, et al. The APACHE III prognostic system. Risk prediction of hospital mortality for critically ill hospitalized adults. Chest. 1991;100:1619-1636. doi: 10.1378/chest.100.6.1619

9. Moreno RP, Metnitz PGH, Almeida E, Jordan B, Bauer P, Campos RA, et al. SAPS 3-From evaluation of the patient to evaluation of the intensive care unit. Part 2: Development of a prognostic model for hospital mortality at ICU admission. Intensive Care Med. 2005;31:1345-1355. doi: $10.1007 /$ s00134-005-2763

10. Farfel JM, Franca SA, Sitta Mdo C, Filho WJ, Carvalho CR. Age, invasive ventilatory support and outcomes in elderly patients admitted to intensive care units. Age Ageing. 2009;38(5):515-520. doi: 10.1093/ageing/afp119

11. Nagappan R, \& Parkin G. Geriatric critical care. Crit Care Clin. 2003;19(2):253-270. doi: 10.1016/s07490704(02)00050-7

12. Nguyen YL, Angus DC, Boumendil A, Guidet B. The challenge of admitting the very elderly to intensive care. Ann Intensive Care. 2011;1(1):29. doi: 10.1186/21105820-1-29

13. Lai CC, Ko SC, Chen CM, Weng SF, Tseng KL, Cheng KC. The Outcomes and Prognostic Factors of the Very Elderly Requiring Prolonged Mechanical Ventilation in a Single Respiratory Care Center. Medicine (Baltimore). 2016;95(2):e2479. doi: 10.1097/ MD.0000000000002479

14. Farfel JM, Franca SA, Sitta Mdo C, Filho WJ, Carvalho CR. Age, invasive ventilatory support and outcomes in elderly patients admitted to intensive care units. Age Ageing. 2009;38(5):515-520. doi: 10.1093/ageing/afp119 
15. Onal O, Ozgun G. Comparison of the course and prognosis of geriatric patients admitted to the intensive care unit according to BMI and albumin values. Anesth Pain Med. 2016;6(1):e32509. doi: 10.5812/aapm.32509

16. Machado Dos Reis A, Marchetti J, Forte Dos Santos A, Franzosi OS, Steemburgo T. NUTRIC Score: Isolated and Combined Use With the NRS-2002 to Predict Hospital Mortality in Critically Ill Patients. J Parenter Enteral Nutr. 2020 Feb 6. doi: 10.1002/jpen.1804 Online ahead of print

17. Liang J, Li Z, Dong H, Xu C. Prognostic factors associated with mortality in mechanically ventilated patients in the intensive care unit: A single-center, retrospective cohort study of 905 patients. Medicine (Baltimore). 2019;98(42):e17592. doi: 10.1097/MD.0000000000017592

18. Esteban A, Anzueto A, Frutos F, Alia I, Brochard L, Stewart ET et al. Characteristics and outcomes in adult patients receiving mechanical ventilation: a 28-day international study. JAMA. 2002;287(3):345-355. doi: 10.1001/ jama.287.3.345

19. Fialkow L, Farenzena M, Wawrzeniak IC, Brauner JS, Vieira SRR, Vigo A. et al. Mechanical ventilation in patients in the intensive care unit of a general university hospital in southern Brazil: an epidemiological study. Clinics (Sao Paulo) 2016;71(3):144-151. doi: 10.6061/clinics/2016(03)05

20. Du B, An Y, Kang Y, Yu X, Zhao M, Ma X et al. Characteristics of critically ill patients in ICUs in mainland China. Crit Care Med. 2013;41(1):84-92. doi: 10.1097/ ccm.0b013e31826a4082

21. Quality of Life After Mechanized Ventilation in the Elderly Study Investigators. 2-month mortality and functional status of critically ill adult patients receiving prolonged mechanical ventilation. Chest. 2002;121(2):549-558. doi: 10.1378/chest.121.2.549

22. Hernu R, Wallet F, Thiollière F, Martin O, Richard JC, Schmitt Z, et al. An attempt to validate the modification of the American-European consensus definition of acute lung injury/acute respiratory distress syndrome by the Berlin definition in a university hospital. Intensive Care Med. 2013;39(12):2161-2170. doi: 10.1007/s00134-013-3122-6
23. Vincent JL, Moreno R, Takala J, Willatts S, De Mendonça A, Bruining $\mathrm{H}$, et al. The SOFA (Sepsis-related Organ Failure Assessment) score to describe organ dysfunction/ failure. Intensive Care Med. 1996;22:707-710. doi: 10.1007/ BF01709751

24. Kao KC, Hsieh MJ, Lin SW, Chuang LP, Chang CH, Hu $\mathrm{HC}$, et al.Survival predictors in elderly patients with acute respiratory distress syndrome: a prospective observational cohort study. Sci Rep. 2018;8(1):13459. doi: 10.1038/s41598018-31811-w

25. Ando K, Doi T, Moody SY, Ohkuni Y, Sato S, Kaneko N. The Effect of Comorbidity on the Prognosis of Acute Lung Injury and Acute Respiratory Distress Syndrome. Intern Med. 2012;51(14):1835-1840. doi: 10.2169/ internalmedicine.51.6434

26. Orsini J, Butala A, Salomon S, Studer S, Gadhia S, Shamian $B$, et al. Prognostic factors associated with adverse outcome among critically ill elderly patients admitted to the intensive care unit. Geriatr Gerontol Int. 2015;15(7):889894. doi: 10.1111 /ggi.12363

27. Harbarth S, Holeckova K, Froidevaux C, Pittet D, Ricou B, Grau GE et al. (2001) Diagnostic value of procalcitonin, interleukin-6, and interleukin-8 in critically ill patients admitted with suspected sepsis. Am J Respir Crit Care Med. 2001;164(3):396-402. doi: 10.1164/ajrccm.164.3.2009052

28. Haas LE, van Dillen LS, de Lange DW, van Dijk D, Hamaker ME. Outcome of very old patients admitted to the ICU for sepsis: a systematic review. Eur Geriatr Med. 2017;8(5):446-453. doi: 10.1016/j.eurger.2017.07.021

29. Martin GS, Mannino DM, Eaton S, Moss M. The epidemiology of sepsis in the United States from 1979 through 2000. N Engl J Med. 2003;348(16):1546-1554. doi: 10.1056/NEJMoa022139

30. Li Q, Gong X. Clinical significance of the detection of procalcitonin and C-reactive protein in the intensive care unit Exp Ther Med. 2018;15(5):4265-4270. doi: 10.3892/ etm. 2018.5960 